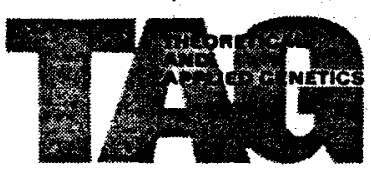

(C) by Springer-Verlag 1981

\title{
Correlated Responses to Selection for Wing Length in Allozyme Systems of Drosophila melanogaster
}

\author{
M. Aguadé, J. Cuello and A. Prevosti \\ Department of Genetics, Faculty of Biology, University of Barclona, Barcelona (Spain)
}

Summary. Significant changes of genotypic structure in 20 lines selected for wing length are detected by analysis of the allelic frequencies of several enzyme loci $(\mathrm{XDH}$, LAP-D, EST-6, 1-APH, ADH, $\alpha$-GPDH). These changes are not haphazard but a consequence of the effects of selection on the genetic structure of the population, since replicate lines always behave in a parallel way. The changes are larger in the lines selected for short wings, in which the genetic variability decreases considerably. This decrease is the result of selection for homozygosity, detected at the allozyme loci, but most probably reflects homozygosity of more or less extended chromosomal segments. Selection for wing length, especially for short wings, favoured recombinants of the initial founder chromosomes. Only in the 1-APH and the EST 6 loci, separated by 11.7 centimorgans on the genetic map, do the alleles linked in the founder lines change in parallel in the control and long wing lines. The correlated response in the allozyme allele frequencies cannot be accounted for by a direct influence of the allozymes on the variability in wing length. The changes in the EST-6, 1-APH and perhaps in the LAP-D, can be explained by a direct effect of natural selection on the allozyme loci, probably in interaction with the effect of selection for wing length on linked loci. This last effect seems to be the main factor contributing to the change detected in the XDH locus.

Key words: Artificial selection - Selection for wing length - Correlated responses to selection - Allozyme systems - Drosophila melanogaster

Introduction

An enormous potential variability in genotypes controlling quantitative traits has been detected in artificial selection experiments. Classical examples of these experiments are those by Mather (1941), selecting on abdominal chaetae of Drosophila melanogaster, Robertson and Reeve (1952) and Reeve and Robertson (1953), on wing and thorax length of Drosophila melanogaster, and Falconer (1953), on body size in mice. Also, numerous changes in nonselected traits, accounted for by pleiotropy or by linkage of the genes controlling the selected characters, have been observed (Mather and Harrison 1949; Prevosti 1958). However, only guesses on the structure of the genotypes controlling these traits and on the relationships between these genotypes and the results obtained, are possible. This situation exists because of the general difficulties confronting the genetics of quantitative traits, arising from the complexity of the genotype controlling these traits and the difficulties in separating the component unit factors. Because of this, the results obtained in experiments with these traits are usually only open to statistical analysis at the phenotypical level, leading subsequently to conclusions about the genotype also only of a statistical nature. Frequently, several alternative models or situations fit these statistical results.

One attempt to go farther than statistical inferences on the genotype was the work by Prevosti (1967), on selection for wing length in Drosophila subobscura in which a control of the frequencies of chromosomal arrangements was carried out in the selected lines. Selection for long wings favoured heterozygous combinations for chromosomal arrangements, whereas selection for short wings generally fixed specific chromosomal arrangements in homozygous combination. These results were considered relevant for explaining the asymmetrical response obtained from the selection: selection for long wings is less effective in changing the mean of the population than selection for short wings.

The results of Lewontin and Hubby (1966) led to the knowledge of the existence of a great amount of genetic variability expressed in differences at the protein level, especially in allozyme systems, detectable with electrophoretic techniques. It is tempting to consider whether or 
not this variability at least partially coincides with that found in quantitative traits. Thus, it appears as possibly rewarding to carry out artificial selection experiments in quantitative traits, determining at the same time the allelic frequencies in some polymorphic allozyme systems. Even if the allozyme loci are not physiologically related to the selected quantitative traits, these loci can serve as markers of chromosome segments furnishing information about the changes in the genotypic structure during selection.

Following this idea we planned selection experiments on wing length in Drosophila melanogaster, measuring at the same time the allelic frequencies in some allozyme systems. The purpose of these experiments was to obtain information at the single locus level, paralleling the data obtained at the level of supergenes in the above mentioned experiments by Prevosti. Some preliminary results have already been presented (Aguadé et al. 1973).

\section{Materials and Methods}

Drosophila subobscura, the species used by Prevosti (1967) for studying the relationships between selection for wing length and chromosomal arrangement frequencies, is not suited for our present purpose. Most individuals of this species are heterozygous for one or several chromosomal arrangements. This peculiarity results in limited recombination between the loci contained in the inversions responsible for the different arrangements or under their influence. This was the reason for choosing Drosophila melanogaster for our experiments. However, obtaining stocks of Drosophile melanogester, from natural populations and thus free of variability in chromosomal arrangements, was not as easy as had been expected. The Spanish populations, from which some of the experimental stocks were extracted, have extensive variability in their chromosomal arrangements.

\section{Origin of the Stocks}

The purpose of these experiments is analytical. We search for information, as precisely as possible, on the effects of selection for a quantitative trait on the structure of the genotype. To obtain this, it is convenient to begin each selection line with the simplest and more definite structure possible: crossing two isogenic or inbred lines. When we cross two isogenic lines initially we have only two chromosomal types - and crossing-over between them is the origin of all the new chromosomes present in successive generations. In crossing inbred lines we have an approximation to this situation.

This known and definite structure of the founder populations better suits the purpose of the present paper than the foundation of populations with a random sample of chromosomes of unknown constitution, which would be more suitable for experiments with other purposes, i.e. trying to simulate natural populations in population cages. Another point of uncertainty that we eliminate by crossing two isogenic or inbred stocks for the foundation of the selection lines, is the possibility of confusing more than one allele within the same electrophoretic mobility. The problem of linkage disequilibrium with other genes would be reduced if a parallel tendency was observed when selecting several populations with different pairs of starting chromosomes.
Table 1 contains the origins and genetite lines used in the foundation of the 5 populates lines used were tested cytologically for the abeots. Normal levels of recombination along the whole to some were also found when making the adequate 0.0 multiple marker stock for that chromosome ( $\mathrm{ru} \mathrm{cu} \mathrm{ca}$ ). Frot population two replicated lines were selected for long wings, th were selected for short wings, and one control was established. These lines, as well as the designation used thereafter for them, are also found in Table 5 .

In the 5 populations, both founding stocks were crossed, resulting in a founding population with frequencies $p=q=0.5$ for each allele in each locus, with the exception of the fifth population, in which the 1-APH locus had a frequency of 0.74 for the fast allele and 0.26 for the slow allele. The experiments were planned to study the four allozyme loci indicated in Table 1, however some data about other loci have been collected for the LX2 and the LXEP lines. The alcohol dehydrogenases (ADH) and atycerophosphate dehydrogenases ( $\alpha-G P D H$ ) have been analysed in the 0 and last (9th) generations of the LX2 lines. The a-GPDH has also been analysed in the 0,3 and last ( 6 th) generations of the LXEP lines. As one of the foundation stocks (3009 from Umed) of the lines LXI and LXEP was homozygous for the visible mutant ebony these lines had the initial frequencies $e^{+}=0.5$ and $e=0.5$. This offered the possibility to measure the changes in the frequencies of the alleles, which has been done in the LXEP lines.

\section{Selection Method}

Five vials containing 100 eggs each, were cultivated every generation in the selected lines. After complete emergence of the adults, 20 of and 20 virgin 99 were randomly sampled, from each of these vials and measured. The 4 individuals of each sex, from each vial, with the longest or shortest wings were selected. So, a total of 20 couples among 100 measured ones were put together and after mating, their eggs were collected in order to obtain the next generation. The control lines were maintained with 15 vials per generation containing 100 eggs each; all the individuals which emerged were mixed and used as parents for the next generation. Although the number of effective parents would be much greater in these control lines than in the selection lines, experiments by Serra (personal communication) show that when the number of parents is twenty pairs, no significant random changes are observed in the gene frequencies of allozymes. The selection was initiated in the $F_{2}$ of the cross between the founder stocks. The techniques of measuring the wing length were the same as those used in previous selection experiments (Prevosti 1956).

The allele frequencies of the allozyme systems were estimated every generation. Samples were of 100 individuals, corresponding to 200 alleles for each locus.

\section{Electrophoretic Technique}

The electrophoretic analysis of the LAP-D locus was carried out using the technique of Beckman and Johnson (1964) modified by Sakai et al. (1969), which utilizes starch gel electrophoresis in a discontinuous system of buffers according to Poulik (1957). The XDH locus was analysed according to the technique of $Y e n$ and Glassman (1965) with minor modifications. The technique of Wright (1963) with modifications by Richmond (1972) was followed in the analysis of the EST-6 locus. The analysis of the 1APH locus was carried out with the technique of Beckman and 
Table 1. Origin, genetic constitution and symbolisin used to designate the selected lines

\begin{tabular}{|c|c|c|c|c|c|}
\hline $\begin{array}{l}\text { Population } \\
\text { number }\end{array}$ & Origin & $\begin{array}{l}\text { Initial genetic } \\
\text { constitution }\end{array}$ & & $\begin{array}{l}\text { Analysed lines } \\
\text { replicate }\end{array}$ & Designation \\
\hline 1. & $\begin{array}{l}\text { Crossing inbred stocks } 3009 \times 3010 \\
\text { from the Genetics Department of } \\
\text { the University of Umea }\end{array}$ & 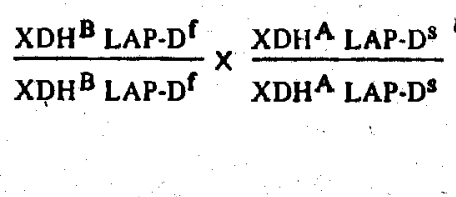 & & $\begin{array}{l}\text { first } \\
\text { second } \\
\text { Control }\end{array}$ & $\begin{array}{l}\text { LX1-1I } \\
\text { LX1-1s } \\
\text { LX1-21 } \\
\text { LX1-2s } \\
\text { LX1-C }\end{array}$ \\
\hline 2. & $\begin{array}{l}\text { Crossing isogenic stocks } 41.7 \mathrm{\Sigma} \times 01.30 \\
\text { from a natural population of Prat de } \\
\text { Llobregat }\end{array}$ & $\frac{X H^{B}{ }_{L A P-D}^{f}}{X D H^{B}{ }_{L A P-D}^{f}} \times \frac{X D H^{A}{ }_{L A P \cdot D}}{X D H^{A}{ }_{L A P \cdot D^{s}}}$ & & $\begin{array}{l}\text { first } \\
\text { second } \\
\text { Control }\end{array}$ & $\begin{array}{l}L X 2-11 \\
L X 2-1 s \\
L X 2-21 \\
L X 2-2 s \\
L X 2-C\end{array}$ \\
\hline 3. & $\begin{array}{l}\text { Crossing isogenic stocks } 12-1 \times 12-2 \\
\text { from a natural population of Prat de } \\
\text { Llobregat }\end{array}$ & $\frac{\text { EST }-6^{f} 1-A P H^{s}}{E S T-6^{f} 1-A P H^{3}} \times \frac{E S T-6^{s} 1-A P H^{f}}{E S T-6^{8} 1-A P H^{f}}$ & & $\begin{array}{l}\text { first } \\
\text { second } \\
\text { Control }\end{array}$ & $\begin{array}{l}\text { EP1-11 } \\
\text { EP1-1s } \\
\text { EP1-21 } \\
\text { EP1-2s } \\
\text { EP1-C }\end{array}$ \\
\hline 4. & $\begin{array}{l}\text { Crossing isogenic stocks } 1 \times 4 \\
\text { from a natural population of } \\
\text { Blanes }\end{array}$ & $\frac{E S T-6^{f} 1-A^{\prime} H^{s}}{E S T-6^{f} 1-A^{3} H^{s}} \times \frac{E S T-6^{s} 1-A P H^{f}}{E S T-6^{s} 1-A P H^{f}}$ & & $\begin{array}{l}\text { first } \\
\text { second } \\
\text { Control }\end{array}$ & $\begin{array}{l}\text { EP2-11 } \\
\text { EP2-1s } \\
\text { EP2-21 } \\
\text { EP2-2s } \\
\text { EP2-C }\end{array}$ \\
\hline 5. & $\begin{array}{l}\text { Crossing inbred stock } 3009 \times \text { isogenic } \\
\text { stock } 01.30 \text { (see } 1 \text { st. and } 2 \text { nd. } \\
\text { population) }\end{array}$ & $\frac{E_{S T-6^{f}} 1-A P H^{f} \times D H^{B} \text { e LAP-D }}{E S T-6^{f} 1-A^{f} H^{8} X H^{B} \text { e LAP-D }} \times$ & 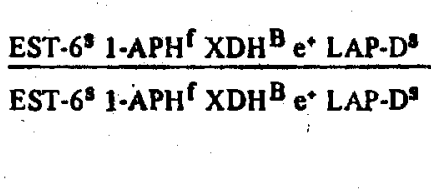 & $\begin{array}{l}\text { first } \\
\text { second } \\
\text { Control }\end{array}$ & $\begin{array}{l}\text { LXEP-11 } \\
\text { LXEP-1s } \\
\text { LXEP-21 } \\
\text { LXEP-2s } \\
\text { LXEP-C }\end{array}$ \\
\hline
\end{tabular}

1 = Selection for long wings; $s=$ Selection for short wings 
Johnson (1964) with the modifications of Wallis and Fox (1968). Starch gel electrophoresis was used for the ADH and a-GPDH loci, with the buffer system of O'Brien and McIntyre (1969); the incubation was carried out with the method of Grell et al. (1965) and Grell (1967), allowing the simultaneous detection of both enzyme systems.

\section{Results}

\section{Effects of the Selection on Wing Length (Fig. 1)}

As is usual in selection experiments in wing length in Drosophila (Robertson and Reeve 1952; Reeve and Robertson 1953; Prevosti 1956, 1967) the response to

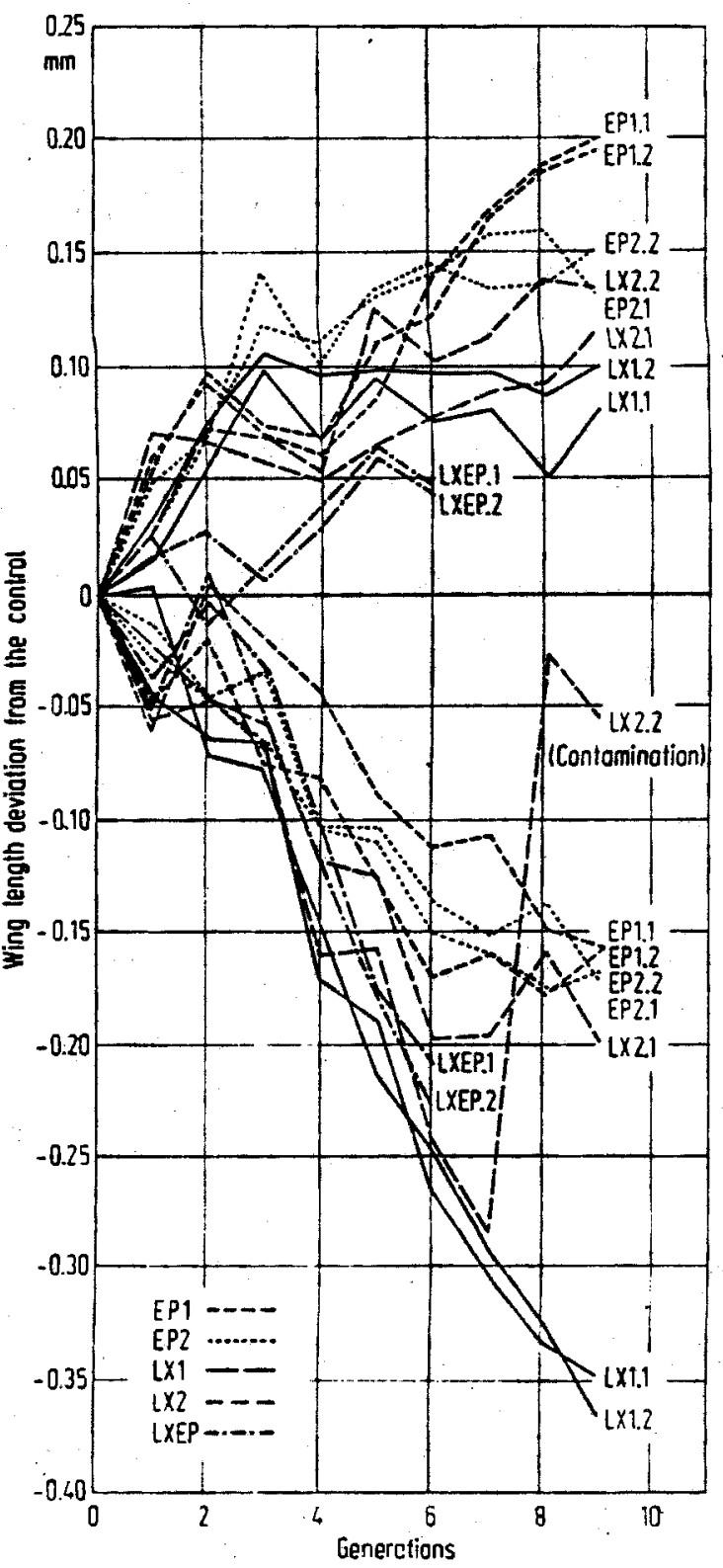

Fig. 1. Deviation of the mean wing length of the selected lines from the controls selection was significant. In a few generations the mean of the selected lines is shifted to values out of the range of individual variation in the founder population.

With the exception of the lines EPI, as in the previous experiments on wing length indicated above, theytings selected for long and short wings initiated simultaneousy from the same population and carried on using identict selection pressures show a clearly asymmetrical response to the selection. The change is greater in the short wing lines: often after 3 to 6 generations of selection in the long wing lines, the response decreases considerably. Apparently two factors contribute to the origin of this asym. metry in the response to the selection. First, the distribution of wing length shows a tendency to be negatively asymmetrical. This is reflected in the selection differentials (Table 2), larger in the s than in the 1 lines in spite of the fact that the same criterion has been used to choose the selected individuals in all lines (see also Prevosti 1956). Second, the heritability is also greater in the $s$ lines. From the data in Table 2 it can be roughly estimated that, on an average, one third of the asymmetry in the response to the selection can be accounted for by the asymmetry of the

Table 2. Cumulative selection differentials ( $\Sigma \Delta s$, in $\mathrm{mm}$.), cumulative responses to selection ( $\Sigma$ responses, in $\mathrm{mm}$.) and realised heritability in the selected lines.

\begin{tabular}{|c|c|c|c|}
\hline & $\stackrel{4}{\omega}$ & 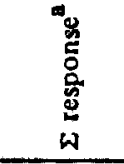 & 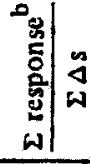 \\
\hline LX $1-11$ & 0.57075 & 0.08000 & 0.140 \\
\hline LXl-1s & 0.67100 & 0.37000 & 0.551 \\
\hline$L X I-21$ & 0.55275 & 0.12000 & 0.217 \\
\hline$L X 1-2 s$ & 0.63625 & 0.33650 & 0.529 \\
\hline LX2-11 & 0.42575 & 0.11025 & 0.259 \\
\hline LX2-Is & 0.59775 & 0.20900 & 0.350 \\
\hline LX2-2l & 0.43750 & 0.14000 & 0.320 \\
\hline$L \times 2-2 s$ & 0.76975 & 0.34800 & 0.452 \\
\hline EP1-11 & 0.88550 & 0.19850 & 0.224 \\
\hline EP1-1s & 1.06925 & 0.17900 & 0.167 \\
\hline EP1-21 & 0.93300 & 0.19475 & 0.209 \\
\hline EPl-2s & 1.02000 & 0.17625 & 0.173 \\
\hline EP2-11 & 0.69550 & 0.17125 & 0.246 \\
\hline EP2-1s & 0.85850 & 0.21875 & 0.255 \\
\hline EP2-2I & 0.65925 & 0.17625 & 0.267 \\
\hline EP2-2s & 0.94600 & 0.23475 & 0.248 \\
\hline LXEP-1i & 0.49675 & 0.06475 & 0.130 \\
\hline LXEP-1s & 0.55325 & 0.02900 & 0.504 \\
\hline LXEP-2I & 0.49425 & 0.05875 & 0.119 \\
\hline LXEP-2s & 0.56300 & 0.25550 & 0.454 \\
\hline
\end{tabular}

a The responses are calculated as the differences between the means of the selected and the control lines.

b For the purpose of the present paper only this raw estimate of the realised heritability has been calculated. 
distribution of wing length, the remaining two thirds depend on the differences in heritability.

In most cases the variance of the distribution of wing length does not show a very clear trend, but in the lines LX2-1s and LX2-2s it increases. In the lines selected for short wings the variability is greater (in a few cases it is similar) than in the control lines. The lines selected for long wings, on the contrary, have usually less variability, especially in the last generations of selection. Obviously, these trends are clearer if we compare the coefficients of variability.

\section{The Allele Frequencies in the Allozyme Loci during} Selection (Table 3, Fig. 2)

The same trehd is found in all lines (Table 3, Fig. 2) selected for long wings, short wings and control, in the EST. 6, the 1-APH and (with the exception of the LX2-s lines) the LAP-D. (The sudden change in the 9th generation of the line $L X 2-2 s$, in which a sharp decrease of the LAP-Ds allele comes after a sharp increase, is due to contamination. This is also detected in the mean wing length of this line, which in the 8th generation suddenly rises almost to its value in the control line.) The EST $-6^{s}, 1-\mathrm{APH}^{\mathrm{f}}$ and LAP-D $D^{f}$ alleles increase. The $\alpha-G P D H^{3}$ allele also increases in all the LX2 lines, independently of the direction in which the selection was applied. However, in the LXEP selected for long wings and control the fast allele increases. In the $\mathrm{XDH}, \mathrm{ADH}$ and ebony loci the changes in the allelic frequencies show an opposite trend in the $s$ and 1 lines. The $c$ lines show rather stable frequencies, with the exception of the $\mathrm{LX} 2$ one, where the $\mathrm{XDH}^{\mathrm{A}}$ allele increases. The fast allele (A) of the XDH decreases in the $\mathrm{LX} 2$ and the LXEP 1 lines, whereas this allele increases in the corresponding s lines. In the $L X 1$ population the reverse situation is found, the fast allele increases in the Ilines and decreases in the $\mathrm{s}$ lines.

In most cases the changes in the allelic frequencies are greater in the $s$ than in the 1 lines.

Finally, an interesting feature of the data in Table 3 is the strikingly parallel way in which the two replicate lines of the same populations constantly change.

\section{Linkage During Selection}

The position on the map of the 3rd chromosome loci here studied is EST-6 36.0, 1-APH 47.7, XDH 52, e+ 70.7, LAP-D 98.3. The lines studied were started by crossing stocks homozygous for two specific types of chromosomes, $\frac{\text { EST- } 6^{f} 1-\mathrm{APH}^{\mathrm{s}}}{\mathrm{EST}-6^{\mathrm{f}} 1-\mathrm{APH}^{\mathrm{s}}} \times \frac{\mathrm{EST}-6^{\mathrm{s}} 1-\mathrm{APH}^{\mathrm{f}}}{\mathrm{EST}-6^{\mathrm{s}} 1-\mathrm{APH}}$ in EP lines, etc. The selection was begun with frequencies 0.5 and 0.5 of
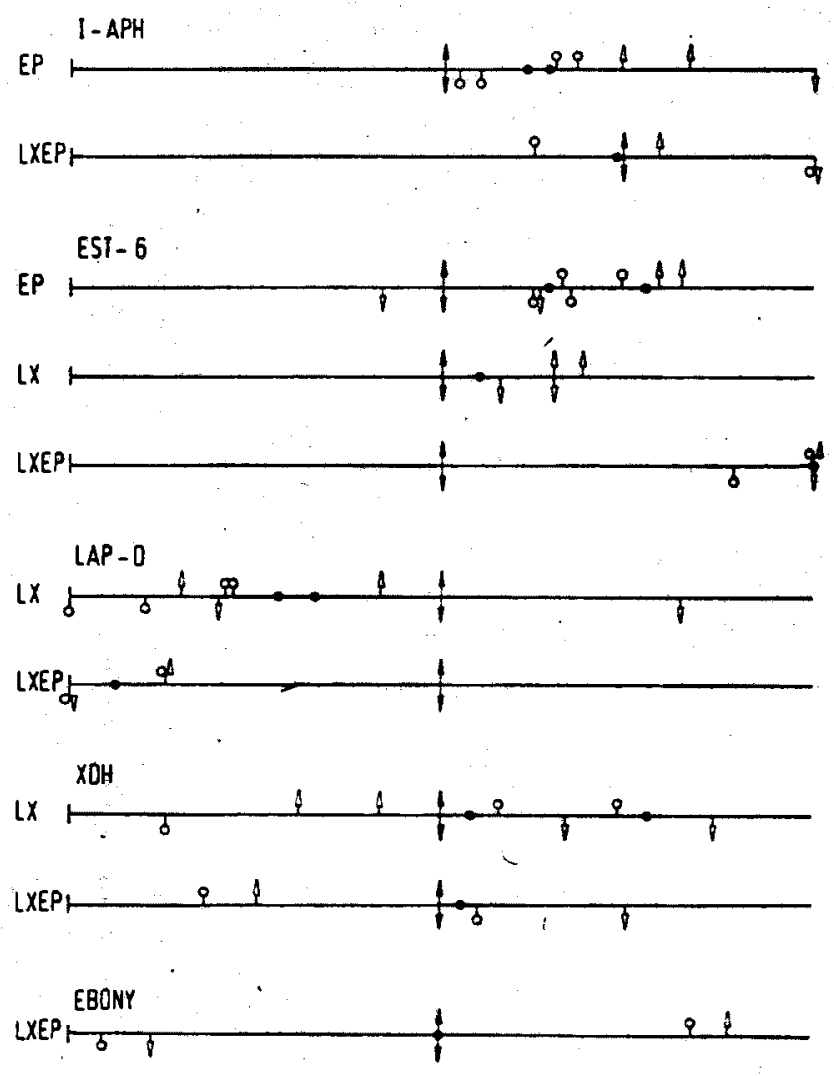

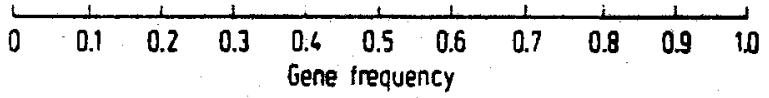

Fig. 2. Final gene frequencies of different allozymes in lines selected for wing length. Starting frequency, which was in most cases 0.5 . Above axis: lines selected for long wings; below axis: lines selected for short wings; points on the axis: control lines. 0 lines number $1 ; \Delta$ lines number 2

gametes carrying these chromosomes, although unfortunately, this has not been always possible to maintain. The parental stock 3009. of the LXEP lines segregates for the 1-APH fast and slow alleles. This is the reason for the following frequencies in generation 0 at this locus: 1-APH $=0.74$ and $1-\mathrm{APH}^{\mathrm{s}}=0.26$. If linkage is close enough, we should expect, at least at the beginning of the selection, some parallelism in the changes of the frequencies of the alleles originally linked. Of course, it is clear that factors other than pure linkage ones could have influence on a parallel change of these alleles. These could be the common linkage of these alleles with a third gene or with several genes at other loci strongly affected by selection or an independent selection in equal sense of both allozyme alleles.

The frequencies given in Table 3 correspond to alleles initially linked in each line. Thus, the data presented in this Table give some indication of the possible influence of linkage on the frequency changes in these alleles. How. 
Table 3. Frequencies of the allozyme alleles, in lines selected for wing length. All frequencies have been estimated from samples of 100 individual $(=200$ alleles)

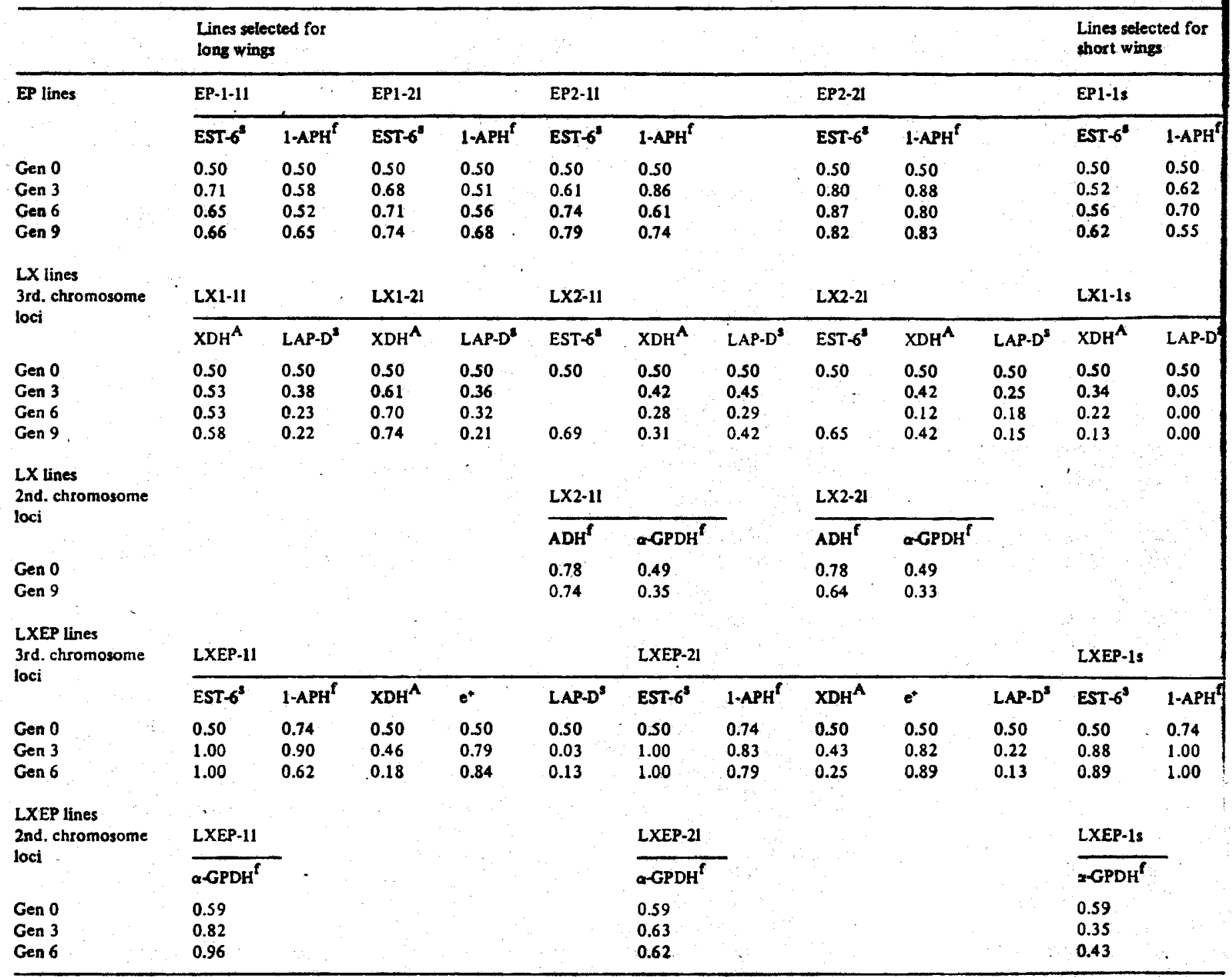

ever, $\chi^{2}$ values have been calculated in order to have a quantitative measure of the parallelism of these changes in pairs of linked loci. The null hypothesis would be that if linkage between the two considered loci was complete, the same frequency should be observed in each generation for each pair of alleles initially linked. An example of this homogeneity test is presented below for a particular case (EPl-11, third generation). In fact, in this generation, the sample size for each enzyme system - EST -6 and 1-APH is 200 genomes, of which 143 have been observed to carry the fast allele of EST-6 and 115 the slow allele of 1-APH (alleles intially linked). If the null hypothesis was correct, the same number 129 .would be expected for each member of this pair of alleles and 71 would also be expected for the members of the other pair.

\begin{tabular}{l|c|c|c}
\hline & \multicolumn{1}{|c|}{ A } & \multicolumn{1}{|c|}{ B } & \\
\hline EST-6 & \multicolumn{1}{|c|}{143} & 57 & 200 \\
\hline & $(129)$ & $(71)$ & \\
$1-A P H$ & 115 & 85 & 200 \\
& $(129)$ & $(71)$ & \\
\hline & 258 & 142 & 400 \\
\hline
\end{tabular}

A. The upper cell of this column corresponds to the frequency of the EST $-6^{f}$ allele and the lower cell to the 1-APH allele, these alleles being associated in the founder population. 
Table 3. (continued)

Lines selected for short wings

\begin{tabular}{|c|c|c|c|c|c|c|c|c|c|c|c|c|}
\hline EPL - 2s & & EP2-1s & . & & EP2-2s & & & EP1C & & EP2-C & & \\
\hline EST $-6^{2}$ & 1-APH ${ }^{f}$ & EST $-6^{4}$ & I-APH & · & EST- $6^{2}$ & 1-APH & & EP-6" & 1-APH & EST $-6^{2}$ & 1-APH & \\
\hline $\begin{array}{l}0.50 \\
0.49 \\
0.64 \\
0.67\end{array}$ & $\begin{array}{l}0.50 \\
0.44 \\
0.49 \\
0.52\end{array}$ & $\begin{array}{l}0.50 \\
0.67 \\
0.87 \\
0.63\end{array}$ & $\begin{array}{l}0.50 \\
0.85 \\
1.00 \\
1.00\end{array}$ & & $\begin{array}{l}0.50 \\
0.62 \\
0.59 \\
0.42\end{array}$ & $\begin{array}{l}0.50 \\
1.00 \\
1.00 \\
1.00\end{array}$ & & $\begin{array}{l}0.50 \\
0.55 \\
0.65 \\
0.64\end{array}$ & $\begin{array}{l}0.50 \\
0.57 \\
0.66 \\
0.61\end{array}$ & $\begin{array}{l}0.50 \\
0.71 \\
0.73 \\
0.77\end{array}$ & $\begin{array}{l}0.50 \\
0.71 \\
0.75 \\
0.64\end{array}$ & \\
\hline$L X 1-2 s$ & & LX2-1s & & & $L \times 2-2 s$ & & & LXIC & & LX2-C & & \\
\hline $\mathrm{XDH}^{\mathrm{A}}$ & LAP-D & EST $6^{2}$ & $\mathrm{XDH}^{\mathbf{A}}$ & LAP-D $D^{3}$ & EST $-6^{3}$ & $\mathrm{XDH}^{\mathrm{A}}$ & LAP-D" & $\mathrm{XDH}^{\mathbf{A}}$ & LAP-D & EST- $6^{3}$ & $\mathrm{XDH}^{\mathbf{A}}$ & LAP-D \\
\hline \multirow[t]{5}{*}{$\begin{array}{l}0.50 \\
0.40 \\
0.26 \\
0.13\end{array}$} & $\begin{array}{l}0.50 \\
0.35 \\
0.23 \\
0.10\end{array}$ & $\begin{array}{l}0.50 \\
0.65\end{array}$ & $\begin{array}{l}0.50 \\
0.74 \\
0.68 \\
0.87\end{array}$ & $\begin{array}{l}0.50 \\
0.43 \\
0.83 \\
0.82\end{array}$ & $\begin{array}{l}0.50 \\
0.58\end{array}$ & $\begin{array}{l}0.50 \\
0.63 \\
0.52 \\
0.67\end{array}$ & $\begin{array}{l}0.50 \\
0.51 \\
0.80 \\
0.20\end{array}$ & $\begin{array}{l}0.50 \\
0.49 \\
0.54\end{array}$ & $\begin{array}{l}0.50 \\
0.41 \\
0.28\end{array}$ & 0.55 & $\begin{array}{l}0.50 \\
0.63 \\
0.78\end{array}$ & $\begin{array}{l}0.50 \\
0.49 \\
0.33\end{array}$ \\
\hline & - & LX2-1s & & 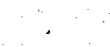 & LX2-2s & & & & & $L \times 2-C$ & & \\
\hline & & $\mathrm{ADH}^{f}$ & $\alpha G P D H^{f}$ & & $A D H^{?}$ & $\alpha-G P D H$ & . & & & $A D H^{f}$ & a-GPDH ${ }^{f}$ & - \\
\hline & & $\begin{array}{l}0.78 \\
1.00\end{array}$ & $\begin{array}{l}0.49 \\
0.33\end{array}$ & & $\begin{array}{l}0.78 \\
1.00\end{array}$ & $\begin{array}{l}0.49 \\
0.24\end{array}$ & $\because$ & & & $\begin{array}{l}0.78 \\
0.88\end{array}$ & $\begin{array}{l}0.49 \\
0.36\end{array}$ & \\
\hline & & & LXEP-2s & & & & & LXEPC & & & & \\
\hline $\mathrm{XDH}^{\mathrm{A}}$ & $e^{+}$ & LAP-D ${ }^{3}$ & EST-6 & 1-APH ${ }^{f}$ & $\mathbf{X D H}^{\mathrm{A}}$ & $e^{+}$ & LAP-D ${ }^{2}$ & EST- $6^{2}$ & 1-APH & $\mathrm{XDH}^{\mathbf{A}}$ & $e^{+}$ & LAP-D \\
\hline $\begin{array}{l}0.50 \\
0.70 \\
0.55\end{array}$ & $\begin{array}{l}0.50 \\
0.03 \\
0.04\end{array}$ & $\begin{array}{l}0.50 \\
0.02 \\
0.00\end{array}$ & $\begin{array}{l}0.50 \\
1.00 \\
1.00\end{array}$ & $\begin{array}{l}0.74 \\
1.00 \\
1.00\end{array}$ & $\begin{array}{l}0.50 \\
0.78 \\
0.75\end{array}$ & $\begin{array}{l}0.50 \\
0.10 \\
0.11\end{array}$ & $\begin{array}{l}0.50 \\
0.03 \\
0.00\end{array}$ & $\begin{array}{l}0.50 \\
1.00 \\
1.00\end{array}$ & $\begin{array}{l}0.74 \\
0.66 \\
0.73\end{array}$ & $\begin{array}{l}0.50 \\
0.50 \\
0.53\end{array}$ & $\begin{array}{l}0.50 \\
0.54 \\
0.50\end{array}$ & $\begin{array}{l}0.50 \\
0.24 \\
0.06\end{array}$ \\
\hline & & & LXEP-2s & & & & & LXEP-C & & & : & \\
\hline & & & $\alpha-G P D H^{\prime}$ & & & & $\therefore$ & $\alpha-G P D H^{f}$ & & & & \\
\hline & & & $\begin{array}{l}0.59 \\
0.50 \\
0.48\end{array}$ & & & & . & $\begin{array}{l}0.59 \\
0.71 \\
0.73\end{array}$ & & & & 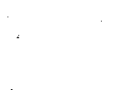 \\
\hline
\end{tabular}

$\mathbf{L} \times 2-$

\section{Control tines}

B. The upper and lower cells of this column correspond respectively to the EST $-6^{5}$ and $1-\mathrm{APH}^{\mathrm{f}}$ alleles, also initially linked.

Because of segregation in the 1-APH locus present in the 3009 stock, it has not been possible in the LXEP population to test the parallelism of the variation of the alleles at this locus and those at the other $3 \mathrm{rd}$ chromosome loci.

According to the mean $\chi^{2}$ values in successive generations (Table 4), only the alleles of the EST-6 and 1-APH in the controls, of the $\mathrm{XDH}$ and $e$ also in the controls and of the LAP-D and $e$ in the short wing lines show similar and not significantly different yariations. Linkage could be invoked to explain this, but parallel selection could also be an explanation. 
Table 4. Means of the $x^{2}$ (with $1 \mathrm{df}$.), testing the homogeneity of allete frequencies of linked pairs of loci, in successive generations of lines selected for wing length

\begin{tabular}{|c|c|c|c|c|c|c|}
\hline $\begin{array}{l}\text { Pairs of loci } \\
\text { compared }\end{array}$ & $\begin{array}{l}\text { 1-APH } \\
\text { EST-6 }\end{array}$ & $\begin{array}{l}\text { XDH, } \\
\text { EST } 6\end{array}$ & $\begin{array}{l}\text { LAP-D } \\
\text { EST-6 }\end{array}$ & $\begin{array}{l}\text { XDH } \\
\text { e }\end{array}$ & $\begin{array}{l}\text { XDH. } \\
\text { LAP-D }\end{array}$ & $\begin{array}{l}\text { LAP-D } \\
\text { e }\end{array}$ \\
\hline Control lines & 1.49 & 128.10 & 297.57 & 0.26 & 41.86 & 56.72 \\
\hline Long wing lines & 7.20 & 206.14 & 311.15 & 100.62 & 29.91 & 201.93 \\
\hline Short wing lines & 44.31 & 45.73 & 348.12 & 158.09 & 66.23 & 1.87 \\
\hline
\end{tabular}

around the equilibrium values $(\simeq 0.70$ ) found in the populations they analysed. Because of this we have tried a model in which we assumed that the fast allele of EST -6 is submitted to a selection coefficient $s=0.22$ (this coefficient fits with the changes observed in this allele) and at the same time we assume that selection has no direct action on the 1-APH locus or any gene closely linked to it. On the basis of these assumptions we calculated how the frequencies of the 1-APH allele should change, exclusively as a result of its linkage with the EST- $6^{f}$ allele in the starting populations.

According to this model, frequencies of 0.303 for the EST $-6^{f}$ and of 0.346 for $1-$ APH $^{3}$ are expected after 9 generations of selection. In experimental data we expect deviations from these values due to the effect of population size, which was not considered in our model. Of course, the model could be made similarly assuming that selection was acting on the 1-APH locus and had no action on the EST-6. Thus, the conclusion is that changes in both loci in the EP control and long wing selected lines can be explained by selection on one locus plus linkage effect on the other, without the latter being necessarily affected by selection. It is evident, however, that other possibilities cannot be excluded. An interesting point is that in the lines selected for short wings this model does not work, indicating that the linkage between the EST-6 and the 1APH loci is completely broken.

The conservation of the initial linkage relationship between the $\mathrm{XDH}$ and the $e$ loci in the control lines is due to the stability observed in the frequencies of both loci in these lines. The parallel changes of the LAP-D ${ }^{s}$ and $e$ alleles are most probably due to selection, whether directly on these alleles or on genes closely linked to them. In the other pairs of loci, no effect of linkage can be detected at all. This is especially striking in the XDH- EST-6 comparison since these loci are only 16.0 units apart.

Considering all comparisons together, the mean $\chi^{2}$ values obtained in the control, long wing and short wing lines are, respectively, $87.67,142.82$ and 110.72 . The higher values in the short and long wing lines indicate that selection for wing length is favouring recombinant chromosomes.

\section{Selection for. Wing Length and Genetic Variability}

The measurement of allozyme allele frequencies, gives some information about what happens to genetic variability in general, when selection for a quantitative trait is performed. This is raluable information independent of the relationships between the corresponding enzymes and the selected trait. The loci controlling the allozyme systems can be considered as points or markers of regions of the chromosomes that can be followed in consecutive generations. In the lines LX1, EP1 and EP2 two loci are considered, five in the $L X 2$ and six in the LXEP.

As an estimation of the genic variability we used the values of $2 \mathrm{pq}$ for each locus. As a general estimation, the mean values of $2 \mathrm{pq}$ for all the loci of each line have been calculated (Table 5). Also, a general mean for the long wings, short wings and control lines, weighted with the number of loci considered in each line, has been calculated. With the exception of the LX2 and EP1 lines the highest

Table 5. Estimation of genetic variability (mean values of $2 p q$ ) in the last generation of selection in lines selected for wing length

\begin{tabular}{|c|c|c|c|c|c|c|}
\hline 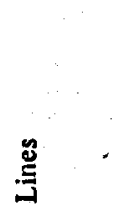 & $\therefore$ & $\begin{array}{l}\overrightarrow{0} \\
0 \\
0 \\
0 \\
0 \\
\dot{0}\end{array}$ & 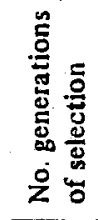 & 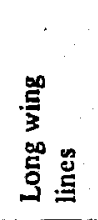 & 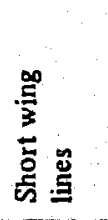 & 员 \\
\hline LX1-1 & & 2 & 9 & 0.415 & 0.113 & \multirow{2}{*}{0.450} \\
\hline LX1-2 & & 2 & 9 & 0.358 & 0.203 & \\
\hline LX2-1 & & 5 & 9 & 0.436 & 0.284 & \multirow{2}{*}{0.390} \\
\hline LX2-2 & & 5 & 9 & 0.420 & 0.323 & \\
\hline EP1-1 & & 2 & 9 & 0.452 & 0.483 & \multirow{2}{*}{0.468} \\
\hline EP1-2 & & 2 & 9 & 0.410 & 0.471 & \\
\hline EP2-1 & & 2 & 9 & 0.358 & 0.233 & \multirow{2}{*}{0.407} \\
\hline $\mathrm{EP} 2-2$ & & 2 & 9 & 0.289 & 0.244 & \\
\hline LXEP-I & & 6 & 6 & 0.223 & 0.210 & \multirow{2}{*}{0.316} \\
\hline LXEP-2 & & 6 & 6 & 0.267 & 0.178 & \\
\hline Weighted & eans & & & 0.363 & 0.274 & 0.406 \\
\hline
\end{tabular}

a The data in this column correspond to controls run parallel with each pair of replicate selected lines 
values of $2 \mathrm{pq}$ are those of the control lines, and with the exception of the EP1 lines, the lowest values are found in the lines selected for short wing. The lines selected for long wings have intermediate values, but approach the controls more than the short wing lines. This situation is reflected in the general means, at the bottom row of Table 5.

The lines were founded with a maximum of genic variability, with $2 \mathrm{pq}$ values of 0.5 in almost all loci, and some loss of variability was the most probable expecta. tion in all the lines. This is actually found, but there are differences attributable to the type of selection. There is a slight decrease in the control lines, in which there are probably more than random oscillations of the gene frequencies. In some of the allozyme systems (EST - 6, 1-APH, perhaps LAP-D) natural selection has changed the initial allelic frequencies. The reduction in variability in the lines selected for wing length is greater, especially when the selection is for short wings. This tendency is especially noticeable considering the frequencies of lines in which fixation of one allele has been reached or approached (a frequency over 0.9 ) by the last generation of selection. Among 34 genes in lines selected for short wings, 10 have reached and 3 have approached fixation. Among the 34 genes in lines selected for long wings only in two lines has one allele been fixed, and in one line one allele has reached a frequency over 0.9 . In the 17 genes of control lines only one case of fixation and one of frequency over 0.9 occurs.

\section{Discussion}

The changes in allele frequencies observed in lines selected for quantitative traits can be the result of several different causes. As a first possibility, the genes concerned may have a direct effect on the selected traits, being part of the polygenic genotype controlling the trait. In this case, if there are two alleles, as in the present case, and these have a different effect on the trait, we expect an increase in the frequency of one allele when we select in one direction and this allele should decrease in the lines selected in the opposite direction, in which consequently the other allele should increase. The same relationship should be found in all the lines selected in the same sense.

A second situation consists in genes having no effect on the quantitative trait, but being very closely linked to genes controlling the trait. In this case, selection acting through the linked genes will cause correlated responses in the frequencies of the genes with no effect on the trait. In some lines the linkage will be with alleles having plus effects on the selected quantitative trait, but in others, there will be minus effect alleles. Thus, the correlated responses can be in opposite directions in lines selected in the same sense. Also, recombination can suddenly change the direction of the correlated response. We would have a very similar situation if the analysed gene had an effect on the quantitative trait, but it would be smaller than on the closely linked ones.

We can envisage a third possibility in which the changes are due solely to natural selection either at these loci or at linked ones. In this case we expect similar changes, at least qualitatively, in all the lines, whatever the directions of the selection for the quantitative trait. Even in the control lines we would expect the same kind of changes.

In a fourth possibility, genes with no or small effects on the quantitative trait, and not or only slightly affected by natural selection, can be subjected to random effects. This situation would bring about irregular changes in the allelic frequencies, and the repeatability of these changes in different lines would be very small, even in the replicates of the same experiment.

Of course some degree of interaction among these situations is to be expected.

The most striking general result obtained in these experiment is the parallel behavior of the replicate lines. This conclusion comes from the consideration of $34 \mathrm{com}$ parisons of homologous loci in replicate lines and excludes the fourth of the above said possibilities: that random effects are important factors of the changes of the allozyme frequencies. The process of selection appears, in these experiments, as being rather deterministic.

This very parallel behaviour of the replicate lines allows us to exclude a major effect of linkage disequilibrium with other genes on the response observed.

In both the EST 6 and 1-APH, the changes are in the same direction in the 15 lines analysed. These lines include the control lines, as well as those selected for short and for long wings. This is completely in agreement with the third possibility envisaged, that natural selection is responsible for these changes. The data on the variability in these allozyme systems, in natural populations, also support this interpretation. The alleles increasing in all the lines, the slow one for esterases and the fast one for 1 APH, have higher frequencies in the natural populations of the species.

The results obtained by Kojima and Yarbrough (1967) agree with our results. Even quantitatively there is some agreement in the case of the esterase. The frequencies reached for the slow allele of this allozyme in the populations EP1 and EP2 are, in general, not far from 0.7 , as in the experiments of the above mentioned authors. In two recent papers by Muhs (1975 a, b) data are presented about the changes in EST-6 and I-APH, in lines selected for temperature and developmental rate. He also found an increase of both the slow allele of EST-6 and the fast one of the 1-APH in all the lines. This also supports the hypothesis that natural selection has an effect on these allozymes.

Proof of the effect of natural selection on the LAP system are not as strong as in the case of the EST-6 and the 1-APH ones. The fast allele, increasing in most lines, is also the most frequent in natural populations (O'Brien and McIntyre 1969). However, in the 
lines LX2-S the fast allele decreases, and this exception arouses some doubt about the validity of the natural selection interpretation.

The changes in the $\mathrm{XDH}$ system fit better with the second situation previously envisaged. The frequencies of its alleles change in opposite direction in the lines selected for short and for long wings: this points to a relationship between wing size and such changes. However, lines selected in the same direction, but from different populations, also show opposite correlated responses in the allelic frequencies of this system. Possibly the XDH locus is closely linked with genes having effects on wing length.

The $A D H, \alpha-G P D H$ and $e$ loci have not been studied in a large enough number of lines to draw any general conclusion about its fitting with the above said models of variation.

Long wings in Drosophila subobscure are associated with heterozygosity, and short wings with homozygosity, of specific chromosome arrangements (Prevosti 1967). This was deduced from selection experiments in which selection for long wings led to frequencies of around 0.5 of two specific chromosomal arrangements, whereas selection for short wings led to fixation of one specific arrangement. According to the data analysed in the present paper the tendency to homozygosity in the lines selected for short wings is also apparent at the level of single loci. Both the greater frequency of fixation of alleles in the s lines and the lower values of the genic variability, as measured with $2 \mathrm{pq}$, are a clear indication of this tendency. Obviously, these data do not imply that selection for short wing favors specifically the homozygosity for the allozyme loci, whose alleles have been fixed. Selection for homozygosity of linked loci explains the situation equally well or perhaps better, since in no case is the first of the previously discussed possibilities supported by the changes of the allozyme allele frequencies, indicating no direct relationships between wing length and these alleles. The allozyme loci can be considered as markers of different chromosomal regions, which can be followed in successive generations of selection, indicating the general trends of change in the genotypic structure of the population, when artificial selection is carried out. On this basis it seems right to conclude that even when there are no supergenes involved, such as the chromosomal inversions of Drosophila subobscura, selection for short wings increases homozygosity along the chromosomes. This increase of homozygosity in the short wing lines probably is the main or at least one of the main causes of the asymmetric response to selection (greater responses in the short wing lines) in the selection experiments for wing length in Drosophila. To support this conclusion it can be argued that the lines EP1, which are one exception in showing no asymmetrical response in the selection for wing length, are also the only ones keeping a greater genetical variability when selected for short wings.

We must also consider that in spite of the decrease of genetic variability in the slines, expressed in the values of $2 \mathrm{pq}$, the phenotypic variability is higher in these lines than in the 1 and $c$ lines; in the LX2-1s and LX2-2s it even increases. Prevosti (1956) found a similar situation. Selection for short wings in Drosophila subob. scura was found to increase the variance in wing length, in spite of the increase of homozygosity for the chromosomal arrangements, observed in these lines. The partition of variance in to genetic and environmental components, on the basis of heritability estimates, indicated an increase of both environmental and genetic variability. A loss of developmental homeostasis or canalization was suggested to explain these results.
On comparing these results with the decrease of $2 \mathrm{pq}$ in the allozyme loci and the decrease in heterozygosity for chromosomal arrangements found in Drosophila subobscure we must remember that we are considering genetic variability at two different levels. In the partition of wing length variance, we obtain an estimate of the expression of genetic variability at the phenotypic level. On the other hand, $2 \mathrm{pq}$ and karyotypic analysis estimate genetic variability at the genotypic level. Between genotype and phenotype there are the developmental processes and we must search for an explanation in these processes. As usually a loss of developmental buffering or canalization follows homozygosity (Lerner 1954), this appears as a likely explanation for the increase in phenotypic variability in the lines selected for short wings. Consequently, in short term selection experiments, like the ones analysed here, the loss of genetic variability is not followed by a loss of capacity to respond to selection at the phenotypic level. During selection, the population displays a phenoty pic plasticity greater than in unselected populations, the loss of genetic variability being compensated by an amplification of its phenotypic expression, on which selection operates. This could be a mechanism allowing adaptation to the new selective forces.

The comparison of the changes in the frequencies of the alleles linked in the founder lines gives information about another aspect of the consequences of selection for wing length on the structure of the genotype. From this comparison it can be deduced that selection favors, in general, recombinants of the initial founder chromosomes, even when these chromosomes have been extracted from the same natural population, as is the case of the EP1, EP2 and $L X 2$ populations. The $\chi^{2}$ values testing independent variation of alleles initially linked, are on an average lower in the control than in the selected lines: the effect of selection favoring recombinants is increased by the selection for wing length. In most cases, the $\chi^{2}$ indicates independent variation at a very high level of significance. This is so even for the alleles of the XDH and EST-6 separated by only 16.0 centimorgans, which, remembering the lack of crossing over in the males of Drosophila, is a rather short distance. One exception is the parallel variation found in the control lines in the 1-APH and EST-6, in which the distance is even smaller ( 11.7 centimorgans). This can be explained by linkage when one locus is subjected to natural selection and the other is neutral. However, our data are not critical in discriminating between this and other alternatives, such as a parallel effect of natural selection on alleles initially linked with both loci. It is evident that this alternative does not fit with the results in the short wing lines, in which the $\chi^{2}$ indicate significant deviations from a parallel change of the initially linked alleles. 


\section{Literature}

Aguadé, M,; Cuelio, J.; Prevosti, A. (1973): Selection for wing length in Drosophila melanogaster and gene frequencies in allozyme systems. Genetics 74,13

Beckman, L.; Johnson, F.M. (1964): Variations in larval alkaline phosphatase controlled by Aph alleles in Drosophita melanogaster. Genetics 49, 825-835

Beckman, L.; Johnson, F.M. (1964): Genetic control of amino peptidases in Drosophile melanogaster. Hereditas 51, 221-230

Falconer, D.S. (1953): Selection for large and small size in mice. J. Genet. 51, 470-501

Grell, E.H. (1967): Electrophoretic variants of alpha-glycerophosphate dehydrogenase in $D$. melanogaster. Science 158, 1319-1320

Grell, E.H.; Jacobsen, K.B.; Murphy, J.B. (1965): Alcohol dehydrogenase in Drosophila melanogaster. Science 149, 80-82

Kojima, K.; Yarbrough, K.M. (1967): Frequency dependent selection at the Esterase-6 locus in Drosophila melanogaster. Proc. Natl: Acad. Sci. (USA) 57, 645-649

Lerner, I.M. (1954): Genetic Homeostasis. Edinburgh: Oliver and Boyd

Lewontin, R.C.; Hubby, J.L. (1966): A molecular approach to the study of genic heterozygosity in natural populations. II. Amount of variation and degree of heterozygosity in natural populations of Drosophile pseudoobscura. Genetics 54, 595-609

Mather, K. (1941): Variation and selection of polygenic characters. J. Genet. 41, 159-193

Mather, K.; Harrison, B.J. (1949): The mainfold effect of selection. Heredity 3, 1-52 and 131-162

Muhs, H.J. (1975a): Isozyme frequencies in longterm selection lines of Drosophile melanogaster. I. Isozyme frequencies of the Esterases (Est) and larval alkaline phosphatases (Aph) in temperature selected lines. Theor. Appl. Genet. 46, 101-108

Muhs, H.J. (1975b): Isozyme frequencies in longterm selection lines of Drosophila melanogaster. 3. Isozyme frequencies of the Esterases (Est) and larval alkaline phosphatases (Aph) in selection lines for short and long developmental rate. Theor. Appl. Genet. 46, 191-195

O'Brien, S.J.; Mclntyre, R.J. (1969): An analysis of gene-enzyme variability in natural populations of Drosophila melanogaster and Drosophila simulans. Am. Nat. 103, 97-114
Poulik, M.D. (1957): Starch gel electrophoresis in a discontinuous system of buffers. Nature 18,1477

Prevosti, A. (1956): Resultados de la selección por alas largas y por alas cortas en dos poblaciones naturales de Drosophila sub. obscure. Genet. Iber. 8, 73-115

Prevosti, A. (1958): Respuestas correlacionadas al seleccionar por la longitud del ala en Drosophila subobscura. Genet. Iber. 10, 1-56

Prevosti, A. (1967): Inversion heterozygosity and selection for wing length in Drosophila subobscura. Genet. Res. 10, $81-94$

Reeve, E.C.R.; Robertson, F.W. (1953): Studies in quantitative inheritance. II. Analysis of a strain of Drosophile melenogaster selected for long wings. J. Genet. 51, 276-316

Richmond, R.C. (1972): Enzyme variability in the Drosophila willistoni group. III. Amounts of variability in the superspecies D. paulistorum. Genetics 70, 87-112

Robertson, F.W:; Reeve, E.C.R. (1952): Studies in quantitative inheritance. $I$. The effects of selection of wing and thorax length in Drosophila melanogester. J. Genet. 50, 414-448

Sakai, R.K.; Yung, D.A.; Scandalios, J.G. (1969): Developmental studies of aminopeptidases in Drosophila melanogaster. Mol. Gen. Genet. 105, 24-29

Wallis, B.B.; Fox, A.S. (1968): Genetic and developmental relationships between two alkaline-phosphatase in Drosophila melanogaster. Biochem. Genet. 2, 141-159

Wright, T.R.F. (1963): The genetics of an esterase in Drosophila melanogaster. Genetics 48, 787-801

Yen, T.T.T.; Glassman, E. (1965): Electrophoretic variants of xanthine dehydrogenase in Drosophila melanogaster. Genetics $52,977-9.81$

Received March 22, 1981

Communicated by A. Robertson

Dr. M. Aguadé

Dr. J. Cuello

Prof. Dr. A. Prevosti

Department of Genetics

Faculty of Biology

University of Barcelona

Barcelona-7 (Spain) 